\title{
Tinjauan tentang splin oklusal untuk terapi gangguan sendi temporomandibula A review about occlusal splint as a therapy for temporomandibular disorders
}

\author{
${ }^{1}$ Ricca Chairunnisa, ${ }^{2}$ Erna Kurnikasari \\ ${ }^{1}$ Departemen Prostodonsia Fakultas Kedokteran Gigi Universitas Sumatera Utara, Medan \\ ${ }^{2}$ Bagian Prostodontik Fakultas Kedokteran Gigi Universitas Padjajaran, Bandung \\ Indonesia
}

\begin{abstract}
An occlusal splint is a removable appliance usually made of acrylic, that fits over the occlusal and incisal surfaces of the teeth in one arch, creating precise occlusal contact with the teeth of the opposing arch. Occlusal splint has several functions, one of which is to temporarily provide an temporary occlusion that allows the temporomandibular joints (TMJ) to make the most othopedically stable joint position. Occlusal splint is also used to protect the teeth and its supportive structure from abnormal forces that may create breakdown and/or tooth wear. Occlusal splint is reversible and noninvasive treatment, which is most important in treating temporomandibular disorders (TMD) with many causative factors involved. Many types of splints have been suggested for the treatment of TMD, but the most frequently used are the stabilization splint and the anterior positioning splint. The purpose of this paper is to describe the types of occlusal splints and indication used for the treatment of TMD.
\end{abstract}

Keywords: occlusal splints, temporomandibular disorder

\begin{abstract}
ABSTRAK
Splin oklusal adalah suatu piranti lepasan yang terbuat dari akrilik, dibuat sesuai dengan permukaan oklusal dan insisal gigi pada salah satu lengkung rahang, dan mempunyai kontak tertentu dengan gigi pada lengkung rahang lawan. Splin oklusal memiliki banyak kegunaan, antara lain untuk menciptakan oklusi sementara yang memungkinkan sendi temporomandibula (STM) berada pada posisi yang paling stabil secara ortopedi. Splin oklusal juga dapat digunakan untuk melindungi gigi dan jaringan pendukungnya dari gaya-gaya abnormal yang dapat merusak dan atau menyebabkan keausan gigi. Splin oklusal merupakan suatu perawatan yang reversibel dan tidak invasif. Hal tersebut sangat penting dalam perawatan gangguan STM yang memiliki banyak faktor kausatif yang kompleks. Berbagai jenis splin telah disarankan untuk perawatan gangguan STM, namun yang paling sering digunakan adalah tipe stabilisasi dan reposisi anterior. Tujuan penulisan makalah ini adalah untuk menjelaskan macam-macam splin oklusal dan indikasinya yang digunakan untuk perawatan gangguan STM.
\end{abstract}

Kata kunci: splin oklusal, gangguan sendi temporomandibula

Koresponden: Ricca Chairunnisa, Departemen Prostodonsia Fakultas Kedokteran Gigi Universitas Sumatera Utara, Jl. Alumni No.2 Kampus USU Padang Bulan, Medan, Indonesia. E-mail: riccachairunnisa@yahoo.com

\section{PENDAHULUAN}

Splin oklusal telah digunakan untuk perawatan adanya gejala-gejala bruksisma dan disfungsi sendi temporomandibula (STM) selama berabad-abad. Tsuga dkk menyatakan $87 \%$ kasus disfungsi STM dengan 2 gejala atau lebih, berhasil diatasi dengan splin. ${ }^{1}$ Perawatan dengan splin oklusal menunjukkan hasil yang bermakna untuk menghilangkan gejala disfungsi STM, mengurangi aktivitas parafungsi dan mencegah keausan gigi. ${ }^{2-5}$ Schmid-schwap ${ }^{3}$ menemukan bahwa splin mempunyai nilai terapi yang sama dengan latihan otot maupun kombinasi splin dan latihan otot dalam perawatan disfungsi STM. Okeson ${ }^{3}$ menulis bahwa efektivitas splin dalam mengurangi gejala-gejala disfungsi STM adalah $70-90 \%$ akan berhasil.

Banyak terapi yang dapat dilakukan untuk mengatasi gejala disfungsi STM, baik terapi yang bersifat reversibel atau ireversibel, secara bedah maupun non bedah. Splin adalah perawatan pilihan, karena bersifat reversibel, tidak invasif, dan lebih murah dibandingkan perawatan yanglain. Efektivitas splin sangat menonjol dibandingkan jenis terapi lainnya. ${ }^{7}$ Menurut Hart Long (1995), splin dengan disain apapun sering menghasilkan pengurangan kepekaan otot pengunyahan dalam waktu singkat. Menurut Pertes, splin oklusal umumnya dipercaya mengurangi beban pada struktur sendi, sehingga memperkecil keparahannya.Penguranganbebanpada sendi dapat mengurangi hiperaktivitas otot. Oleh karena itu, splin oklusal sangat membantu dalam pengurangan gejala nyeri sendi STM. ${ }^{8}$

Pada kajian pustaka ini akan dibahas mengenai penggunaansplin oklusal untuk terapi gangguan sendi temporomandibula

\section{TINJAUAN PUSTAKA Splin oklusal}

Istilah splin oklusal atau piranti oklusal adalah permukaan oklusal tiruan lepasan dari plastik atau 
metal yang digunakan pasien secara sementara untuk mengubah kontak oklusal danpolafungsi mandibula. Splin oklusal bertujuan untuk membuat kontak yang seimbang dan harmonis di antara gigi posterior dan mempertahankan posisi sentrik atau terapeutik dari mandibula melalui interkuspasi maksimal pada splin. Splin oklusal adalah suatu piranti yang kaku atau fleksibel yang terbuat dari akrilik transparan, yang diletakkan pada permukaan oklusal dan insisal pada salah satu lengkung rahang,yang dapat menghasilkan kontak oklusal yang tepat dengan gigi pada lengkung rahang lawannya. ${ }^{3,7}$

Kegunaan yang utama dari splin oklusal dari seluruh jenis perawatan oklusal adalah bahwa oklusi dapat diubah meskipun membutuhkan modifikasi ireversibel pada gigi alami penderita. Splin oklusal dapat secara efektif digunakan untuk melindungi gigi dari abrasi akibat bruksisma, menghilangkan gangguan oklusi, menstabilkan hubungan gigi dan sendirahang,mengurangi aktivitas otot, mengurangi frekuensi parafungsi, mengurangi beban STM, memperbaiki koordinasi neuromuskular, perawatan nyeri miogenik atau nyeri bersumber dari sendi, memperbaiki fungsi STM, mengembalikan dimensi vertikal, mempertahankan posisi mandibula definitif yang telah ditetapkan, mengubah pola pergerakan mandibula, menguji skema oklusal yang telah direncanakan pada posisi sentrik dan eksentrik, splin gigi yang lemah, mendistribusikan beban pada kasus bruksisma, dan memperjelas faktor etiologi oklusi pada saat membuat diagnosis banding. 2,3,7,9-13

Aturan dalam insersi splin adalah retensi harus adekuat dan pasif, bentuk splin harus setipis mungkin dan tidak mengganggu jaringan periodonsium, tanpa mempengaruhi stabilitas dan fungsi oklusal, harus dapat mensimulasikan relasi seperti relasi setelah dibuat restorasi akhir, dan perawatan splin oklusal dengan diagnosis yang tidak spesifik, tidak terkontrol maupun terlalu lama akan menyebabkan perubahan permanen pada sistem mastikasi, seperti karies, penyakit periodontal, pergerakan gigi, dan perubahan morfologi sendi. ${ }^{6}$

\section{Klasifikasi splin oklusal}

Secara umum, splin oklusal diklasifikasikan menjadi dua jenis, yaitu splin permisif dan splin direktif., ${ }^{9,14}$

Splin permisif (Gambar 1A), yaitu splin dengan permukaan rata yang memungkinkan otot untuk memindahkan kondilus ke relasi sentrik tanpa interferens yang diakibatkan inklinasi gigi yang defleksi.Splin permisifmemungkinkan gigi bergerak bebas pada splin sehingga kepala kondilus dan diskus berfungsi secara anatomis. Yang termasuk dalam jenis ini adalah splin stabilisasi dan splin gigitan anterior. ${ }^{9,14}$

Splin direktif atau nonpermisif (Gambar 1B), adalah splin yang mengembalikan pada kondisi relasi oklusal yang seharusnya dan posisi kondilus yang seharusnya. Splin ini mempunyai indentasi pada permukaan oklusal, mengarahkan mandibula ke anterior dan inferior serta mempertahankannya pada posisi tersebut. ${ }^{9,14}$

Variasi bentuk splin bermacam-macam, untuk itu pemilihan splin didasarkan pada pertimbangan klinis, misalnya pada penderita yang mengalami kelainan periodontal di anterior yang akan cenderung untuk flaring, untuk kondisi ini dianjurkan untuk penggunaan piranti oklusal rahang atas. ${ }^{8}$

Diantara sekian banyak jenis splin oklusal yang disarankan untuk perawatan TMD, terdapat dua jenis splin yang paling sering digunakan, yaitu splin stabilisasi dan splin reposisi ke anterior. Splin stabilisasi disebut juga splin relaksasi otot karena digunakan untuk tujuan mengurangi nyeri otot. Sedangkan splin reposisi ke anterior disebut juga dengan splin reposisi ortopedik karena bertujuan mengubah posisi mandibula terhadap kranium. ${ }^{3,10,12}$
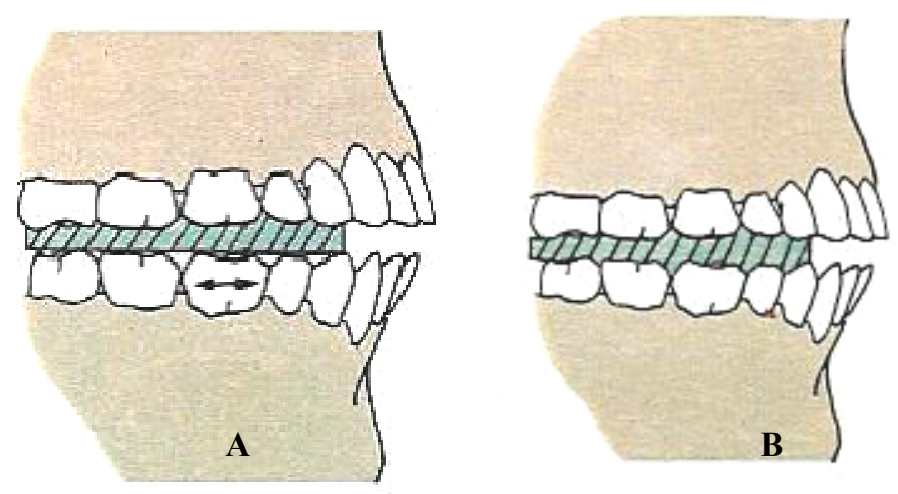

Gambar 1A Splin permisif, B splin direktif (Sumber: Dawson, Peter E. The concept of complete dentistry. St. Petersburg: Dawson Centre of Advanced Dental Surgery). ${ }^{14}$ 


\section{Splin stabilisasi}

Splin stabilisasi (gambar 2A) adalah splin yang tujuan utamanya untuk menormalkan tonus otot mastikasi dan sekaligus mendistribusikan gaya oklusal secara merata. Splin relaksasi disebut juga splin relaksasi otot dan muscle conditioning splint. Al-Ani et $a 1^{15}$ menyimpulkan bahwa splin stabilisasi dapat mengurangi nyeri wajah pada saat istirahat, palpasi dan dekompresi lebih baik daripada tanpa perawatan. Gavish ${ }^{16}$ mengemukakan bahwa splin stabilisasi mempunyai efek terapi yang lebih tinggi dibandingkan plasebo terhadap nyeri masticatory myofacial. Lobbezzoo ${ }^{17}$ menemukan bahwa setelah insersi piranti splin stabilisasi, terlihat bahwa otot temporalis anterior mengalami penurunan aktivitas (Gambar 2B).

Aksi terapeutik dari splin relaksasi (Gambar 3A,B) adalah terjadi dengan mengeliminasi kontak prematur sentrik dan eksentrik, membuat restorasi dukungan yang hilang di posterior, mengurangi terjadinya abrasi,mengarahkan mandibula pada pola pergerakan yang lebih vertikal. Perubahan tonus otot selama praperawatan menyebabkan perubahan relasi rahang, sehingga hal ini menghasilkan kontak oklusal yang baru. Relasi rahang yang nyaman, stabil, dengan keseimbangan neuromuskular hanya dapat dicapai setelah penyesuaian oklusi yang berulang pada splin relaksasi. Rahang bawah yang settling in ini disebut sebagai otoreposisi mandibula (Gambar 3B,D). ${ }^{7}$

Prosedur pembuatan splin stabilisasi dimulai dengan pencetakan dan pembuatan model rahang, pencatatan lengkung wajah, pembuatan gigitan wax pada relasi sentrik (gambar 4A),pemasangan model pada artikulator (Gambar 4B), lalu bloking daerah undercut, membuat pola wax dari splin, curing, pemasangan splin, dan penyesuaian. ${ }^{10}$ Dewasa ini berkembang metode baru yang lebih praktis untuk membuat splin, yaitu dengan teknik vacuforming (Gambar 5 dan Gambar 6).
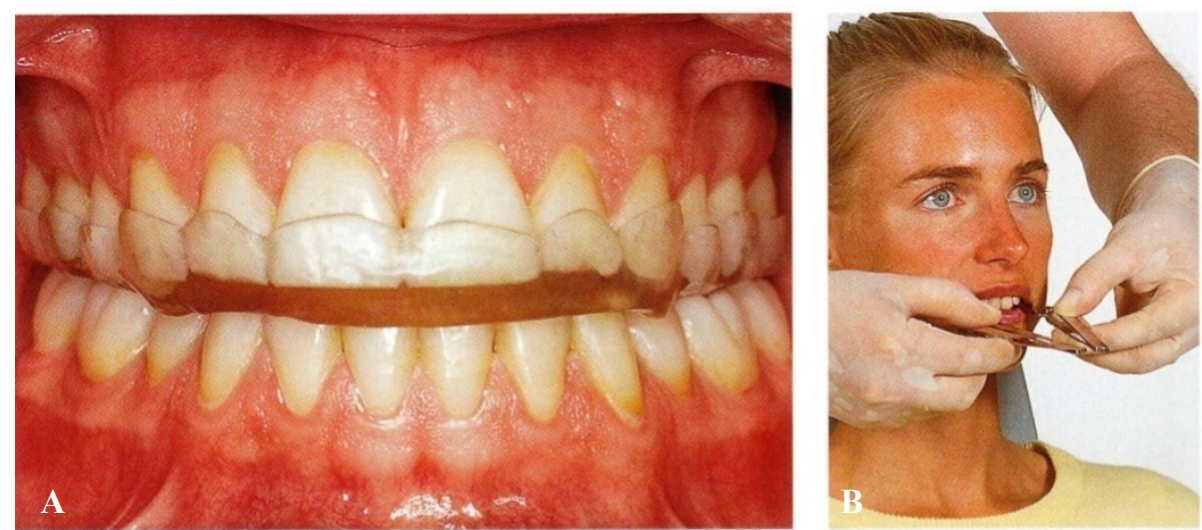

Gambar 2 Splin stabilisasi maksila; A permukaan splin oklusal dibuat rata. Idealnya, permukaan oklusal posterior meyentuh puncak tonjol fungsional dari gigi antagonis. B selama tahap perawatan pendahuluan, kontak prematur pada splin harus diperiksa dan disesuaikan secara berulang (Sumber: Bumann A, Lotzmann U. Color atlas of dental medicine, TMJ disorders and orofacial pain: The role of dentistry in a multidiciplinary diagnostic approach. New York: Thiemme; 2002.p.306). ${ }^{7}$
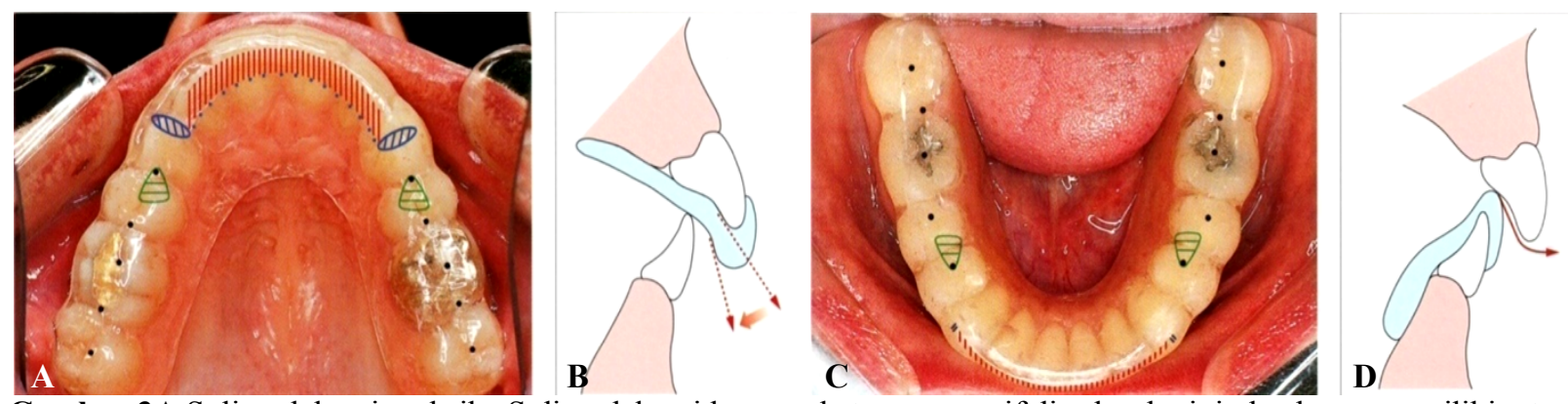

Gambar 3A Splin relaksasi maksila. Splin relaksasi harus cekat secara pasif di seluruh gigi, dan harus memiliki retensi yang adekuat, B splin relaksasi mandibula. Jika panduan anterior pasien akan dipertahankan, splin mandibula mempunyai keuntungan tambahan, yaitu pemasangannya tidak mengubah permukaan lingual gigi insisivus dan kaninus maksila (Sumber: Bumann A, Lotzmann U. Color atlas of dental medicine, TMJ disorders and orofacial pain: The role of dentistry in a multidiciplinary diagnostic approach. New York: Thiemme; 2002.p.306). ${ }^{7}$ 

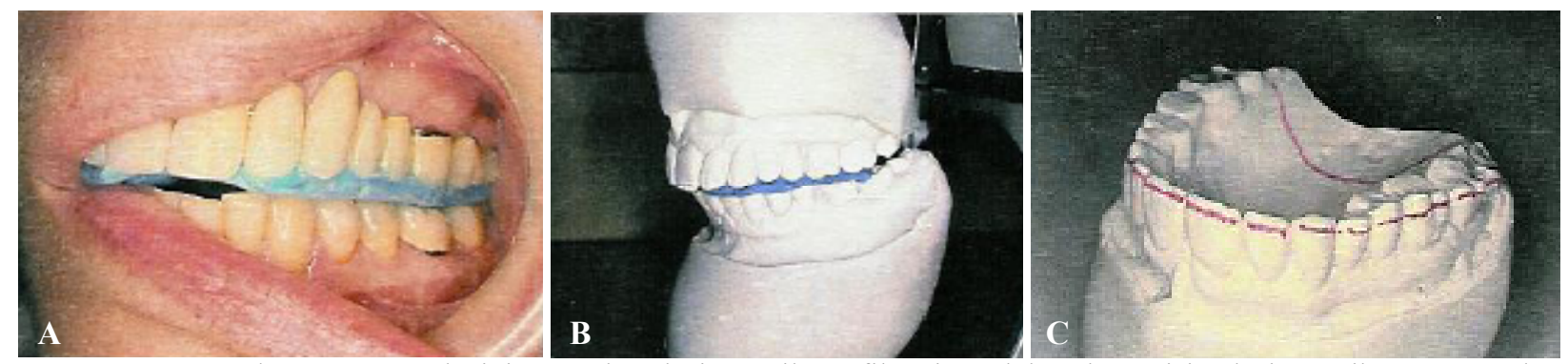

Gambar 4A Pembuatan tanggul gigitan pada relasi sentrik, B fiksasi model pada posisi relasi sentrik menggunakan facebow, $\mathbf{C}$ membuat outline daerah yang menutupi basis (Sumber: Bumann A, Lotzmann U. Color atlas of dental medicine, TMJ disorders and orofacial pain: The role of dentistry in a multidiciplinary diagnostic approach. New York: Thiemme; 2002.p.306.
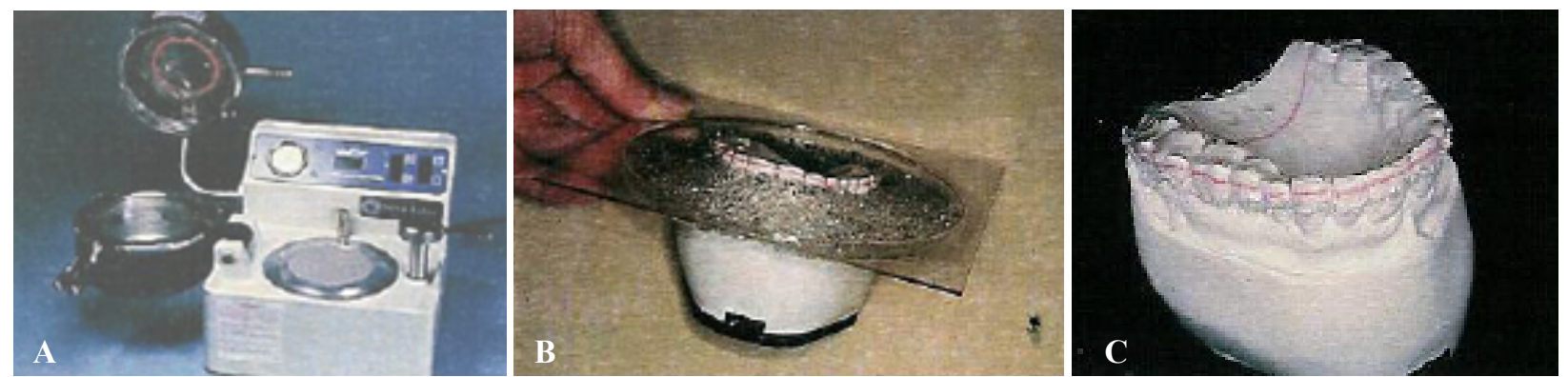

Gambar 5A Alat vacuum untuk pembuatan, B basis Biostar vinyl pada model kerja, C kelebihan bahan dibuang (Sumber: Bumann A, Lotzmann U. Color atlas of dental medicine, TMJ disorders and orofacial pain: The role of dentistry in a multidiciplinary diagnostic approach. New York: Thiemme; 2002.p.306.
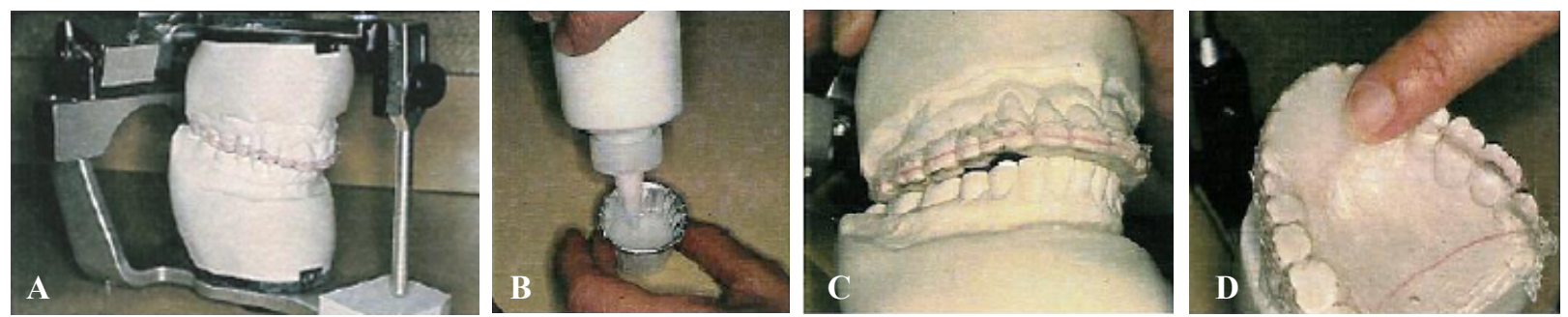

Gambar 6A Letakkan model kerja dan landasan pada artikulator. Buka pin cukup untuk memisahkan semua gigi posterior dari kontak dengan landasan. Karena model dipindahkan dengan facebow, perubahan vertikal tidak mempengaruhi relasi sentrik, B campurkan akrilik dan $\mathbf{C}$ posisikan di belakang gigi anterior rahang atas. Letakkan resin secukupnya untuk kontak dan diterakan dengan gigi anterior rahang bawah pada relasi sentrik, D diamkan hingga setting (Sumber: Bumann A, Lotzmann U. Color atlas of dental medicine, TMJ disorders and orofacial pain: The role of dentistry in a multidiciplinary diagnostic approach. New York: Thiemme; 2002.p.306).

\section{Splin reposisi}

Splin reposisi merupakan piranti oklusal yang dipasang untuk mereposisi diskus secara parsial maupun total ke posisi yang lebih anterior pada saat geligi berada dalam interkuspasi maksimal. Splin reposisi disebutjuga splin reposisi ortopedik, anterior repositioning splint, dan anteropositioning splint. Interkuspasi maksimal dari splin reposisidibuatpada posisi mandibula terapeutik, yaitu posisi mandibula yang paling posterosuperior dengan relasi diskuskondilus yang benar. Posisi mandibula terapeutik selalu berada lebih anterior dari posisi interkuspasi maksimal seorang penderita. Posisi terapeutik tidak dapat ditentukan, kecuali diskus bergeser kembali secara spontan melalui kepala kondil dengan bunyi kliking yang dapat didengar atau dipalpasi selama pergerakan mandibula. ${ }^{7.17}$

Tindakan manipulasi secara bimanual dan aksiografi paraoklusal dapat menghasilkan posisi mandibula yang pergerakannya bebas dari kliking. Relasi diskus-kondilus yang sebenarnya secara lebih nyata dapat terlihat dengan menggunakan MRI (Gambar 7A). Meskipun demikian, splin reposisi tidak boleh diindikasikan jika diskus dari sendi telah bergeser ke anterior dalam waktu yang relatif lama, dan zona bilaminar telah beradaptasi dengan baik, serta penderita tidak merasakan adanya tekanan (Gambar 7B). ${ }^{7}$ 


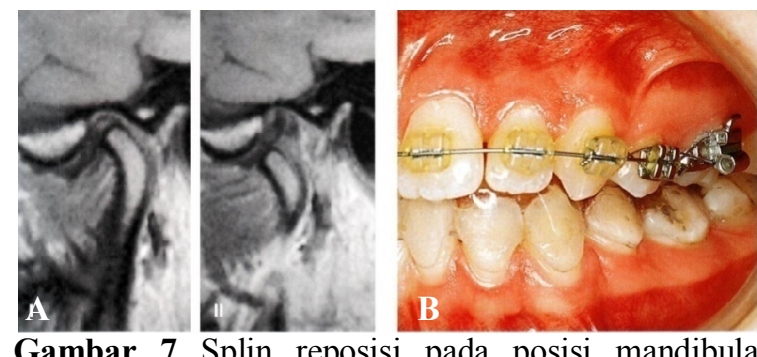

Gambar 7 Splin reposisi pada posisi mandibula terapeutik;AMRIdari diskus-kondilus pada interkuspasi maksimal (I) dan posisi splin terapeutik (II) pada saat perawatan pendahuluan dimulai. Perawatan lanjutan menghasilkan posisi diskus-kondilus yang lebih sentral dan stabil melalui pemeriksaan berulang $\mathbf{B}$ splin reposisi harus dipakai sehari penuh untuk melindungi sendi dari relapsnya kondilus ke zona bilaminar (Sumber: Bumann A,Lotzmann U.Coloratlas of dental medicine, TMJ disorders and orofacial pain: The role of dentistry in a multidiciplinary diagnostic approach. New York: Thiemme; 2002.p.306). ${ }^{7}$

\section{PEMBAHASAN}

Pemilihan splin oklusal(Gambar8) bergantung pada diagnosis yang spesifik dari gangguan TMJ dan pemahaman yang menyeluruh dari anatomi diskuskondilus. Pemasangan splin, di rahang atas atau rahang bawah, dipengaruhi oleh beberapa prinsip dasar Sebaiknya splin ditempatkan pada lengkung rahang yang paling banyak mengalami kehilangan dukungan. Hal tersebut ditujukan agar diperoleh stabilisasi maksimal dengan banyaknya titik kontak oklusal. Pada kasus Klas II Angle atau kasus yang terdapat overjet yang besar,sebaiknya splin dipasang pada rahang atas. Jika splin dibuat pada rahang bawah, akan sulit untuk mencapai kontak anterior maupun penuntun anterior dengan tepat.Penggunaan splin pada rahang bawah lebih disarankan bagi pasien yang menggunakan splin selama 24 jam sehari, karena splin rahang bawah lebih tidak terlihat dan tidak mengganggu proses bicara dibandingkan splin rahang atas. Splin rahang bawah memungkinkan lidah berada pada posisi yang benar, yaitu pada palatum. Pada kasus disfungsi lidah, splin rahang bawah sangat membantu untuk mengangkat lidah kepada posisinya yang paling tepat. ${ }^{6,9,10,12}$

Apakah suatu splin oklusal harus mempunyai indentasi? Ada tidaknya indentasi tergantung pada indikasi splin itu sendiri.Splin permisif seperti splin stabilisasi dan splin gigitan anterior (anterior bite splint/ABS) memiliki permukaan yang rata dan mulus untuk memungkinkan pergerakan rahang secara bebas. Sedangkan splin nonpermisif (splin direktif) seperti splin reposisi mempunyai indentasi pada permukaan oklusalnya, dengan tujuan dapat mempertahankan posisi baru kondilus terhadap kranium. ${ }^{9,10,12}$

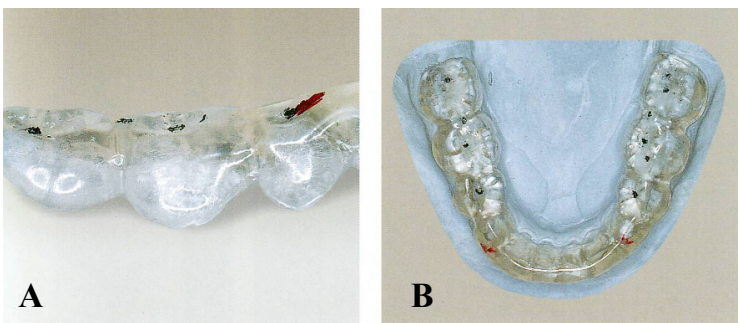

Gambar 8 Desain oklusal; A faset retrusi bilateral yang simetris pada regio premolar menjamin disoklusi gigi posterior layaknya mandibula diarahkan oleh permukaan gigi ke posterior di luar interkuspasi terapeutik dari splin, B posisi terapi mandibula dikunci dengan interkuspasi maksimal splin, yang bebas dari hambatan. Sebagian besar beban oklusal jatuh pada regio posterior.Panduan oklusi anterior atau setidaknya panduan kaninus harus diupayakan pada splin (Sumber: Bumann A, Lotzmann U. Color atlas of dental medicine, TMJ disorders and orofacial pain: the role of dentistry in a multidiciplinary diagnostic approach. New York: Thiemme; 2002. p.306). ${ }^{7}$

Apakah splin oklusal harus dibuat penuh atau sebagian saja? Kekurangan splin parsial,yaitu dapat menyebabkan migrasi ireversibel (ekstrusi, intrusi, dan laterotrusi) akibat tidak adanya stabilisasi dari rahang antagonis. Ukuran splinnya yang kecil dapat menyebabkan splin tertelan bila digunakan saat tidur. Oleh karena itu, splin harus dibuat meliputi seluruh gigi pada satu lengkung rahang. Splin imidiat adalah pengecualian, yaitu splin ini dibuat langsung tanpa melalui pencetakan. Bagaimanapun juga splin imidiat tidak dapat digunakan lebih dari 2 minggu karena menyebabkan migrasi gigi atau maloklusi iatrogenik. ${ }^{9,10}$

Bahan apa yang sebaiknya digunakan untuk pembuatan splin, bahan yang keras atau lunak? Sejak diperkenalkan oleh Matthews pada tahun 1942 hingga saat ini,splin dari bahan lunak atau soft splint sering digunakan. ${ }^{9,10}$ Soft splint mempunyai keuntungan, antara lain pembuatannya lebih mudah dan lebih cepat. Namun soft splint juga mempunyai kerugian, yaitu memicu hiperaktivitas otot, ${ }^{3}$ mudah mengalami kerusakan, dan sulit untuk mencapai keseimbangan sehingga mengakibatkan hubungan antar rahang yang tidak terkontrol. Lalu Pettengil ${ }^{18}$ menemukan bahwa soft stabilizing splint dan hard stabilizing splint mempunyai hasil yang sama dalam mengurangi nyeri otot mastikasi, untuk jangka waktu pemakaian yang pendek.

Disimpulkan bahwa piranti splin oklusal adalah permukaan oklusal tiruan lepasan dari akrilik yang digunakan pasien secara sementara untuk merubah kontak oklusal dan pola fungsional mandibula.Splin oklusal dibuat untuk memperoleh kontak seimbang 
Tabel 1 Perbandingan ketiga jenis splin ${ }^{12,15}$

\begin{tabular}{|c|c|c|c|}
\hline Jenis splin & Splin imidiat & Splin stabilisasi & Splin reposisi \\
\hline Prinsip & $\begin{array}{l}\text { Penetapan keseimbangan } \\
\text { neuromuskular dalam } \\
\text { kondisi emergensi. }\end{array}$ & $\begin{array}{l}\text { Meningkatkan kesadaran } \\
\text { pasien dan merelaksasi otot }\end{array}$ & $\begin{array}{l}\text { Memposisikan kondilus ke anterior dan } \\
\text { inferior untuk mengurangi inflamasi di } \\
\text { daerah retrokondil }\end{array}$ \\
\hline Indikasi & Gejala TMD akut & $\begin{array}{l}\text { Sebagai perawatan awal semua } \\
\text { kasus TMD yang menetap. } \\
\text { Nyeri miogenik. }\end{array}$ & $\begin{array}{l}\text { Anterior disc displacement with reduction } \\
\text { Untuk kasus splin stabilisasi tidak efektif }\end{array}$ \\
\hline Pembuatan & $\begin{array}{l}\text { Langsung dibuat di klinik, } \\
\text { tanpa pencetakan, tanpa } \\
\text { artikulator. }\end{array}$ & $\begin{array}{l}\text { Dibuat pada relasi sentrik, } \\
\text { menggunakan artikulator, } \\
\text { permukaan oklusal rata, kontak } \\
\text { seimbang di seluruh gigi }\end{array}$ & $\begin{array}{l}\text { Dibuat pada posisi mandibula ke anterior } \\
\text { dan inferior, menggunakan artikulator, } \\
\text { permukaan memiliki indentasi }\end{array}$ \\
\hline Pemakaian & $\begin{array}{l}\text { Seharian kecuali makan dan } \\
\text { sikat gigi, selama 3-4 hari }\end{array}$ & $\begin{array}{l}\text { Sepanjang hari atau pada saat } \\
\text { tidur, minimal } 2 \text { bulan. }\end{array}$ & Sepanjang hari minimal 3 bulan. \\
\hline
\end{tabular}

di antara gigi posterior dan mempertahankan posisi sentrik atau posisi terapeutik dari mandibula melalui interkuspasi maksimal pada splin.Splin yang paling banyak digunakan adalah splin stabilisasi, splin reposisi dan splin imidiat. Ketiga splin tersebut mempunyai indikasi dan tujuan masing-masing.

Splin oklusal pada saat yang sama harus estetis, nyaman, stabil dan fungsional. Perawatan dengan menggunakan splin oklusal sebaiknya didahului dengan diagnosis spesifik, karena perawatan yang tak sesuai diagnosis,tidak terkontrol maupun terlalu lama akan menyebabkan perubahan permanen pada sistem mastikasi,seperti karies,penyakit periodontal, pergerakan gigi, dan perubahan morfologi sendi. Setiap praktisi sebaiknya memahami dengan benar bahwa splin oklusal tidakmenyembuhkan,melainkan perawatan awal dari suatu penatalaksanaan secara komprehensif pada TMD.

\section{DAFTAR PUSTAKA}

1. Tsuga K, Akagawa Y, Sakaguchi R, Tsuru H. A short term evaluation of the effectiveness of stabilization-type occlusal splint therapy for spesific symptoms of temporomandibular joint dysfunction syndrome. J Prosthet Dent 1989; 61: 610-3.

2. Kaplan, Assael.Temporomandibular disorders:diagnosis and treatment.Philadelphia:WB.Saunders Co.;1991.p. 395.

3. Okeson. Management of temporomandibular disorders and occlusion. Chicago: Mosby Year Book; 1998.

4. Wright, Edward F. Manual of temporomandibular disorders $2^{\text {nd }}$ ed. Iowa: Willey-Blackwell; 2010.p. 470-86.

5. Kurnikasari E. Efektifitas perawatan tahap awal dengan splin oklusal dan korelasi antara gejala-gejala pada disfungsi temporomandibula [Thesis]. Bandung: Universitas Padjadjaran; 1995.

6. Schmid-schwad M.Treatment of patients with temporomandibular disorders. A retrospective treatment comparison. J Stomatol Occl Med 2009; 2: 59-64.

7. Bumann A, Lotzmann U. Color atlas of dental medicine, TMJ disorders and orofacial pain: The role of dentistry in a multidiciplinary diagnostic approach. New York: Thiemme; 2002.p.306.

8. Hart LJ. Diagnostic tests used in determining the role of the occlusion in temporomandibular joint disorders. $J$ Prosthet Dent 1991; 66: 541-3.

9. Dylina TJ. A common-sense approach to splint therapy. J Prosthet Dent 2001;86:539-45.

10. Cap NJ. Occlusion and splint therapy. Br Dent J 1999; 186 (5) 217-22.

11. Orthlieb JD. Eight question on intraoral splint concepts: an interview with Prof. Jeffrey P. Okeson. J Stomatol Occl Med 2009; 2: 57-8.

12. Re JP. The occlusal splint therapy. J Stomatol Occl Med 2009; 2: 82-6.

13. Rodrigues PC. Partial time use of anterior positioning splints in management of TMJ pain dysfunction: a one year controlled study. J Appl Oral Sci 2005; 13(4): 345-50.

14. Dawson, Peter E. The concept of complete dentistry. St. Petersburg: Dawson Centre of Advanced Dental Surgery.

15. Al-Ani Z. Stabilization splint therapy for the treatment of temporomandibular myofascial pain:a systematic review. J Dent Ed 2005; 69 (11): 1242-50.

16. Dao TT, Lavigne GJ. Oral splints: the crutches for temporomandibular disorders and bruxism? Crit Rev Oral Biol Med 1998; 9: 345-51.

17. Lobezzoo F. The effect of an occlusal stabilization splint and the mode of visual feedback on the activity balance between jaw elevator muscles during isometric contraction. J Dent Res 1993; 72: 876-82.

18. Pettengil CA. A pilot study comparing the efficacy of hard and soft stabilizing appliances in treating patients with temporomandibular disorders. J Prosthet Dent 1998; 79: 165-8. 